\title{
Peritoneal Dialysis Catheter-Associated Peritonitis
}

National Cancer Institute

\section{Source}

National Cancer Institute. Peritoneal Dialysis Catheter-Associated Peritonitis. NCI

Thesaurus. Code C114751.

Infection of the peritoneum related to a peritoneal dialysis catheter. 